\title{
Organophosphorous poisoning complicated with intermediate syndrome- A case report
}

\author{
Hussain Asraf', Ansari P2, Adhikari $\mathrm{K}^{3}$, Bista $\mathrm{S}^{4}$, Khirhari J5
}

'Lecturer, ${ }^{2}$ Lecturer, ${ }^{3-5} \mathrm{PG}$ residents, National Medical College and Teaching Hospital, Birgunj, Nepal

Keyword: Organophosphorus poisoning,

intermediate syndrome

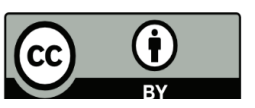

This work is licensed under a Creative Commons Attribution 4.0 Unported License.

\begin{abstract}
Organophosphorous poisoning is a very common poisoning. Intermediate syndrome with respiratory failure is a highly fatal complication. We report a case of 20 year old male who developed intermediate syndrome despite adequate atropinisation. Early clinical recognition of the syndrome and institution of mechanical ventilation along with ongoing atropine therapy was instrumental in saving the patient's life. Patient was discharged on day 10 after successful treatment.
\end{abstract}

\section{Introduction}

According to a WHO stat approximately three million pesticide poisoning occurs worldwide and cause more than 40000 deaths per year.(1) Newer review articles report that number of deaths and casualties attributed to organophosphate pesticide worldwide is about 300000.(2) Developing countries report alarming rates of toxicity and death. This is probably because of easy availability of highly toxic pesticides at the moment of stress. $(3,4)$ Poisoning is a very common cause of medical admissions and deaths in Nepalese hospitals.(5-12) Organophosphorus compounds are most common form of poisoning in Nepal.(13-14)

Case report

A male nursing student of 20 years was admitted to ICU through
Corresponding Author:

Asraf Hussain, Department of Internal Medicine

National Medical College and Teaching Hospital (NMCTH),

Birgunj, Nepal

Email: asrafjeevanjyoti2060@gmail.com 
casualty department with alleged history of consumption of chlorpyrifos $50 \%$. He consumed the compound with suicidal purpose following quarrel with his girlfriend. At the time of arrival about four hours after consumption of compound patient was semiconscious with GCS of 12 . His pulse was $64 / \mathrm{min}$ regular, BP was $100 / 60 \mathrm{mmHg}$, RR was $22 / \mathrm{min}$. Pupils were three $\mathrm{mm}$ and reactive to light. Chest auscultation revealed crepitations all over lung field. He was treated as per standard protocols. After atropinisation patient improved with GCS of 15, vitals within normal limits, chest clear. Patient was shifted to ICU with maintenance dose of atropine and PAM. On third day morning patient deteriorated despite of adequate atropinisation. Patient developed weakness of limbs, was unable to hold his head, saturation dropped to $82 \%$ even with supplemental oxygen, RR dropped to 12/min. ABG reports showed $\mathrm{CO} 2$ retention with decreased level of oxygen. Clinical diagnosis of intermediate syndrome was made. Patient was intubated and put on mechanical ventilation. Atropinisation was continued. PAM was discontinued on day four. On day five patient showed signs of improvement. He was gradually weaned off from ventilator and was extubated on day seven. Atropine was gradually tapered and stopped on day nine. Patient was discharged on day 10 after psychiatry consultation.

\section{Discussion}

OP poison induced Intermediate syndrome (IMS) was first described by Wadia et al as type II paralysis.(15) Term IMS was coined by Senanayake and Karalliedde.(16) IMS was initially described as syndrome of muscular paralysis occurring in conscious patients 24-96h after ingestion. Muscle weakness predominantly affects proximal limb muscles and those supplied by the cranial nerves. It is often associated with respiratory failure. Few recent works suggest that IMS could occur before $24 \mathrm{~h}$ and also after $96 \mathrm{~h}$.(1618) The incidence of IMS has been reported to be between 20$68 \%$.(19) such delayed manifestations are reported to occur due to acetylcholinestrase aging, defective rephosphorylation and decreased synthesis of new enzymes. IMS carries high mortality if presents with respiratory failure. Treatment of IMS is mainly supportive, early aggressive gastrointestinal decontamination, followed by appropriate therapy of atropine and oximes, and prompt institution of ventilatory support, should be helpful in ameliorating the magnitude and/or the incidence of IMS. Fresh frozen plasma,obidoxime $(20,21)$, whole blood transfusion are proposed therapy with better survival in various studies.

\section{Conclusion}

IMS is a fairly common complication of OP poisoning. It carries high mortality if respiratory failure occurs in the patient. Early clinical diagnosis of the syndrome is very crucial. Supportive therapy remains cornerstone in management of IMS. Prompt instillation of Mechanical ventilation along with adequate atropine therapy is life saving.

\section{References}

1. Jeyaratnam J (1990) Acute pesticide poisoning: a major global health problem. World Health Stat Q 43: 139-144

2. Harvey RA, Champe D. Lippincott's illustrated Reviews: Pharmacology, 4th ed. USA: Lippincott Williams and Wilkins; 535p.

3. Darren M, Roberts, Cynthia K. Managing acute Organophosphorus pesti cide poisoning. BMJ 2007; 334:629-34.

4. Karalliedde L, Eddleston M, Murray V. The global picture of organophosphate poisoning. In: Karalliedde L, Feldman F, Henry J, et al. eds. Organophosphate and health.
London: Imperial Press;2001. p. 432-71.

5. Paudyal BP. Poisoning: Pattern and Profile of Admitted Cases in a Hospital in Central Nepal. J Nep Med Assoc 2005;44:9296.

6. Kafle KK, Gyawali KK. Organophosphorus- Commonest Poisoning Agent. J Inst Med 1992; 14: 228-233

7. Prasad PN, Karki P. Poisoning cases at TUTH emergency; a one-year review. J Inst Med 1997; 19: 18-24

8. Ghimire RH, Sharma SP, Pandey KR. A Retrospective Study of the Changing Trends of Poisoning Cases at Tribhuvan University Teaching Hospital, Nepal Between 1990-1992 and 2000-2002. J NHRC

9. Subedi BK. A Retrospective Study of Poisoning Cases at Bir Hospital, Nepal. J Inst Med 1990; 12: 296-302

10. Pokhrel N, Gurung CK. A Study of Poison Cases Recorded in Bir Hospital Over Four Years. J J Inst Med 1987; 29-34

11. Rauniyar GP, Das BP, Naga Rani MA, Gupta MP, KarkiBMS. Retrospective Analysis of Profile of Acute Poisoning Cases in a Tertiary Care Hospital in Eastern Nepal: A Four-Year Database from 1994 to 1997. J Nep Med Assoc 1999; 38: 23-28

12. Pathak UN, Chhetri PK, Dhungel S, Chokhani R, Devkota KC, Shrestha BO et al. Retrospective Study of Poisoning Cases Admitted in Nepal Medical College Teaching Hospital. Nep Med Col J 2001; 3: 101-5

13. Shrestha B, Singh PM, Bharati U, Dhungel S. Poisoning at Nepal Medical College and Teaching Hospital Nepal Med Coll J 2011 Sep; 13(3): 199-204

14. Gupta S K, Joshi M P Pesticide poisoning case attending five major hospitals of Nepal

15. Wadia RS, Sadagopan C, Amin RM. et al neurological manifestation of organophosphorous insecticide poisoning. J.neurol neurosurg.psychiatry 1974; 37; 841-7.

16. Eddleston M, Mohamed F, Davies JO, Eyer P, Worek F, et al. Respiratory failure in acute organophosphorus pesticide self-poisoning. QJM. 2006;99:513-522.

17. He F, Xu H, Qin F, Xu L, Huang J, et al. Intermediate myasthenia syndrome following acute organophosphates poisoning-an analysis of 21 cases. Hum Exp Toxicol. 1998;17:40-45.

18. Avasthi G, Singh G. Serial neuro-electrophysiological studies in acute organophosphate poisoning: correlation with clinical findings, serum cholinesterase levels and atropine dosages. J Assoc Physicians India. 2000;48:794-799.

19. Leon $S$, Fidas Espadrille $G$, et al.neurological effects of organophosphorous pesticides. BMJ 1996;313:690-1. 12.

20. Guven M, Sungur M, Eser B, Sari I, Altuntas F. The effects of fresh frozen plasma on cholinesterase levels and outcomes in patients with organophosphate poisoning. J Toxicol-Clin Toxicol 2004;42:617-23. 13.

21. Chen JG. The therapeutic effects of obidoxime chloride on intermediate syndrome following acute organophosphate poisoning. Zhonghua Xiandai Zhong Xi Yi Za Zhi (Chin J Curr Tradit West Med) 2004;2:945-6. [In Chinese] 